\title{
Real-Time Data Assimilative Modeling on Georges Bank
}

Daniel R. Lynch, Christopher E. Naimie, Justin T. Ip, Craig V. Lewis Dartmouth College - Hanover, New Hampshire USA

Francisco E. Werner, Richard A. Luettich, Jr., Brian O. Blanton, John Quinlan University of North Carolina - Chapel Hill, North Carolina USA

Dennis J. McGillicuddy, Jr., James R. Ledwell, James Churchill, Valery Kosnyrev Woods Hole Oceanographic Institution - Woods Hole, Massachusetts USA

Cabell S. Davis, Scott M. Gallager, Carin J. Ashjian Woods Hole Oceanographic Institution - Woods Hole, Massachusetts USA

R. Gregory Lough, James Manning National Marine Fisheries Service - Woods Hole, Massachusetts USA

Charles N. Flagg Brookhaven National Laboratories - Upton, New York USA

Charles G. Hannah Fisheries and Oceans Canada, Bedford Institute of Oceanography - Dartmouth, Nova Scotia Canada

Robert C. Groman USGLOBEC NWAtlantic Program • Woods Hole, Massachusetts USA

\begin{abstract}
Real-time oceanic forecasts were constructed at sea on Georges Bank during Spring 1999. Ship- and shorebased computations were combined to deliver daily 3day forecasts to shipboard scientists for interpreting observations and planning operations. Data assimilated included acoustic Doppler current profiler velocities, drifter trajectories, and taxa-specific plankton observations from a Video Plankton Recorder (VPR) system. Services provided included basic 3-D circulation forecasts, forecast positions of drifters, dye and zooplankton, and the advective adjustment of observations to produce synoptic maps. The results indicate that real-time, at-sea data assimilative modeling can provide valuable information services and can be deployed routinely, provided that networking among ships, instruments, and shore continues to improve.

This paper summarizes the real-time modeling experience. Results of the larger effort including scientific data interpretation are being reported separately.
\end{abstract}

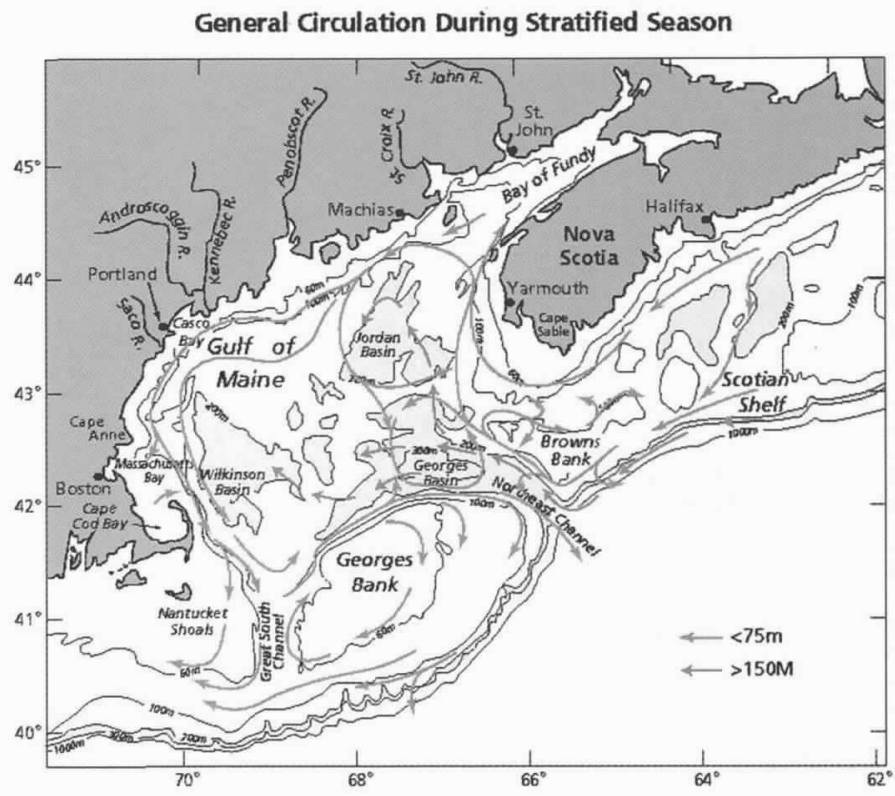

Figure 1. Seasonal circulation in the Gulf of Maine (source: McGillicuddy et al., 1998). 

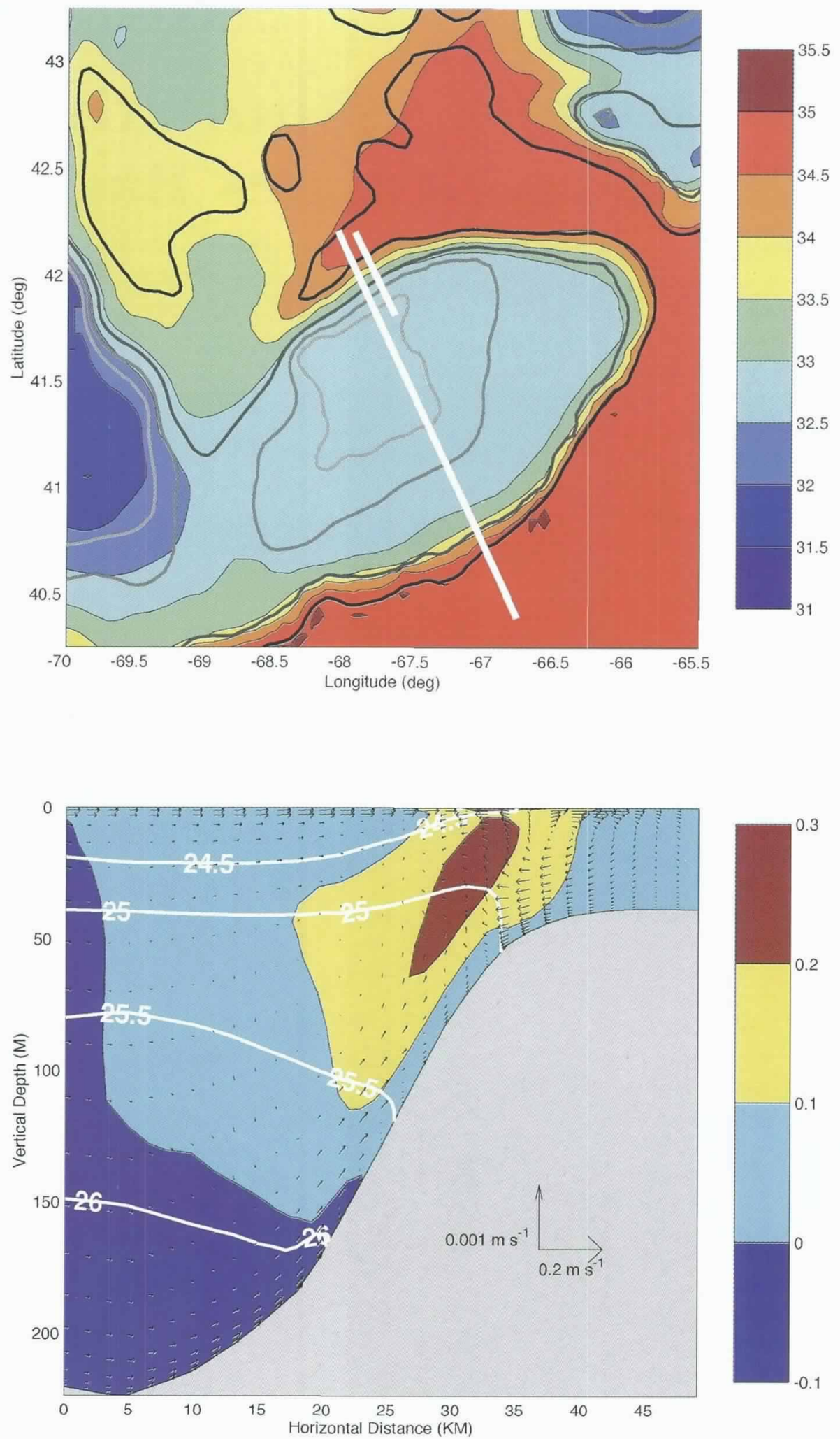

Figure 2. Georges Bank hydrography and circulation, from the computed May-June climatology. Top: bottom salinity ( $p s u$ ) map illustrates the distribution of slope water and fresher shelf water. Bottom: mean subtidal circulation on a transect across the Northern Flank of Georges Bank. The fields are sampled from the simulated climatology. Color bands: isotachs of along-bank speed $(\mathrm{m} / \mathrm{s})$. Vectors: in-plane circulation; Contour lines: $\sigma_{t}$ The transect is marked in the top panel.

\section{Introduction}

The USGLOBEC NWAtlantic program is focused on coupled biological/physical interactions on Georges Bank. The Bank is situated at the shelf break at the border between Canada and the USA, and defines the seaward extent of the Gulf of Maine (Figure 1). The Georges Bank fishery has been a commercially important resource since European contact. The region is a biogeographic transition zone between cold, northern waters and the more temperate environment to the southwest. It has been the subject of numerous oceanographic investigations throughout the century, culminating most recently in the landmark volume edited by Backus and Bourne (1987).

GLOBEC investigations of the Bank began around 1990 with early planning documents and modeling studies (GLOBEC 1991, 1992). These early studies identified four target species for detailed studies: larval cod and haddock, and the copepods Calanus finmarchicus and Pseudocalanus spp. The field effort began in 1994 with the juxtaposition of a) periodic broadscale surveys of the Bank, sampling on a regular pattern of roughly 30 stations within the 150 meter isobath; and b) single-year process-focused observations.

Modeling activities during most of the program have focused on historical data and their scientific interpretation. Among other things, modeling studies have established climatological mean physical fields and perturbations to them and examined the impacts of these on the life history of specific planktonic species and their interactions. A large number of these studies have used the climatological physics to explore key underlying hypotheses of the program. Figures 2 and 3 illustrate these climatological fields.

In 1999, the final GLOBEC field program was devoted to detailed scrutiny of cross-frontal exchange processes. The frontal regime on the 


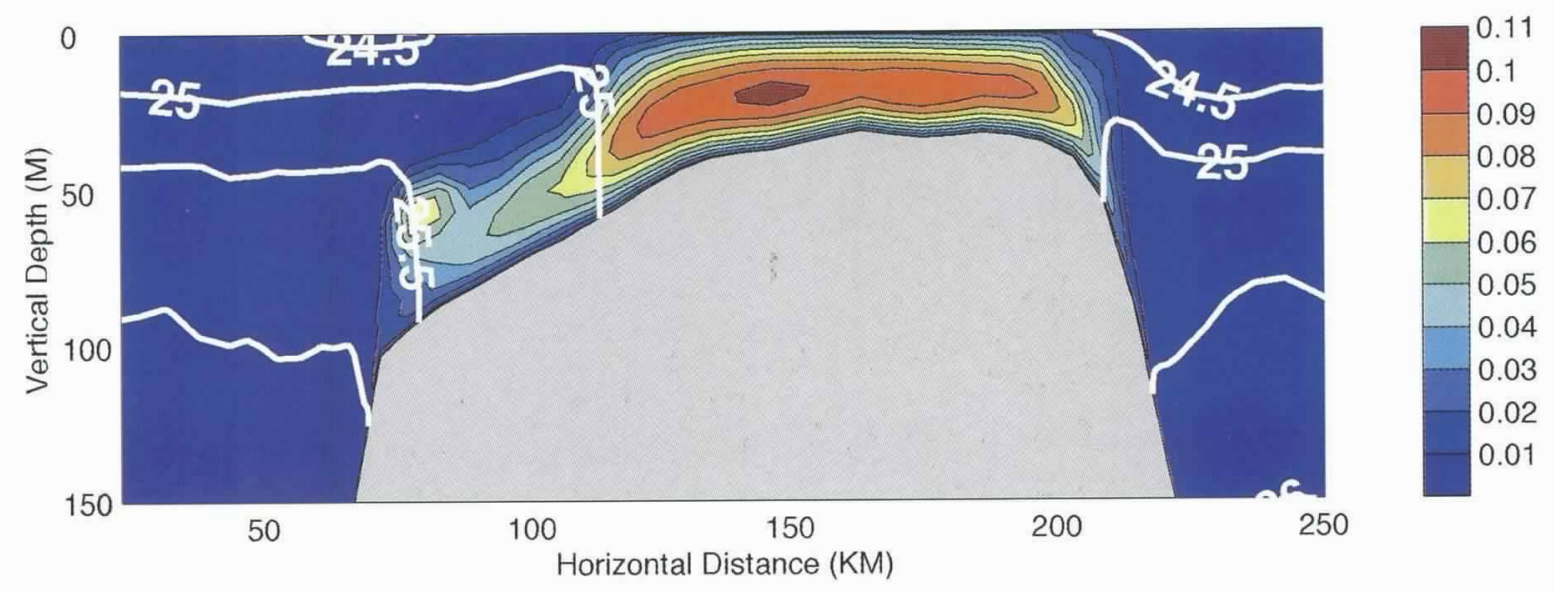

Figure 3. Tidally-averaged density ( $\sigma_{t}$ contours) and vertical viscosity (colorbands, $\mathrm{m}^{2} / \mathrm{s}$ ) over Georges Bank, from the computed May-June climatology. The transect is marked in Figure 2. The viscosity is calculated using level 2.5 turbulence closure and is primarily the result of bottom-generated turbulence due to tidal motion.

bank is highly complex. On the South Flank, a shelf/slope front separates warm, salty slope water from cold, fresher shelf water. Near bottom, this front is typically located between the 70- and 100-meter isobath, with its surface expression further seaward. The bank top is completely mixed in all seasons by tidal turbulence. In summer, a tidal-mixing front surrounds the central bank separating the well-mixed central region from adjacent stratified waters. Rectification of strong tidal currents creates anticyclonic flow along the steep bank sides. On the North Flank, this circulation is merged with the general cyclonic circulation of the Gulf of Maine. The tidally-rectified flow and seasonal tidalmixing fronts combine to create a partial recirculation around the bank, which is most intense in late summer. These features are expressed strongly in the computed climatology, Figures 2 and 3. Important disturbances of these features include episodic wind events, invasion of Scotian Shelf water across the Northeast Channel, perturbations of the shelf/slope front (see Figure 4), and the interaction of Gulf Stream rings with the South Flank features. Taken together, we have a partly closed gyre surrounding the bank with multiple and complex controlling dynamics.

The complexity of these cross-frontal processes demanded the greatest realism possible, both in interpreting observations in hindsight as well as at-sea, in order to better inform the observational scientists about the system they were measuring. Accordingly, it was decided to take the models and the modelers to sea, and to make the best possible estimates of oceanic conditions in realtime, blending all available data and models.

Four GLOBEC cruises were identified for at-sea trials. Each had its own scientific mis- sion, as described in Table 1. The real-time modeling activity was appended to these.

\section{Hypotheses}

The at-sea experience was viewed as a computational "experiment" in itself. Three interrelated hypotheses were framed:

- A practical nowcast/forecast system can be constructed and delivered to shipboard scientists. (Practical in this context means better than climatology and fast);

- A data-assimilative hindcast can improve interpretation of necessarily sparse data;

- A real-time forecast can improve ocean sampling of water, dye, and planktonic organisms.

It is important to recognize 1) that there are imperfections in all models, in all data, and in all sampling plans; and 2) that a theoretically optimal solution to ocean state estimation and forecasting is infeasible today. The emphasis of the project has therefore been on developing a practical procedure, which can be implemented in today's technology, and defining its limits.

\section{Nested Domains}

There are three nested computational domains, representing bank, shelf, and oceanic scale calculations. The oceanic and bank meshes are shown in Figure 6.

We focused our real-time efforts on the limited-area bank-scale domain. This is terminated at the 150 meter isobath and includes most of the routine survey stations and most other GLOBEC sampling. For the North Flank dye release, the mesh was extended northward to better accommodate the local dynamics. and to make the best possible estimates of oceanic conditions

in real-time, blending all available data and models. 


\section{TABLE I \\ Participating cruises}

\section{R/V EDWIN LINK 9904, April I4-25 1999}

The mission was to examine circulation, hydrography, and ichthyoplankton distributions and transport in the South Flank tidal front system. This was a first, exploratory cruise for the Real-Time Data Assimilation (RTDA) project.

\section{R/V ENDEAVOR 323, 324, May 4-June 81999}

These cruises were focused on cross-frontal exchange processes. Three dye injection experiments were conducted in the tidal mixing fronts of the South and North Flanks; two on the South Flank, with one injection near-surface and the second in the pycnocline, and the third on the North Flank with a dye release in the pycnocline (Figure 5). The hydrography, dye concentration, and distribution of planktonic taxa were described in relation to the fronts using the Video Plankton Recorder.

\section{R/V EDWIN LINK 9905, May I0-3I, 1999}

This cruise was focused on ichthyoplankton distributions and transport in the South Flank frontal system, as a follow up to the previous survey EL9904. This cruise overlapped with dye releases I and 2 of EN 323/4, providing an opportunity to test real-time operations distributed among two ships.

Initial and boundary conditions (BCs) for this mesh are critical. Our default condition is our model-computed climatology, available as an on-line archive from previous studies (Naimie, 1996). Included are hydrography, pressure, velocity, and turbulent mixing rates. These fields were computed on a shelf-wide mesh which includes the Gulf of Maine and the Scotian Shelf. The May-June climatology is sampled in Figures 2 and 3 . In the absence of observations, this serves as our best estimate of the ocean state and is used to initialize and force (through BCs) the bank-scale simulations. In the cases reported here, hydrographic data from recent bank-wide surveys were available (Figure 4) and we used these instead of the climatological hydrography.

A critical concern was to correctly simulate the widearea response to atmospheric forcing, as it affects the bank-scale boundary conditions. To do this we conducted a separate set of 2-D, barotropic ocean-scale simulations, forced by tides and atmospheric model outputs. The oceanic mesh contained the waters west of the $60^{\circ} \mathrm{W}$ meridian including the Western North Atlantic, Caribbean Sea and Gulf of Mexico. The northwestern portion of this mesh is depicted in Figure 6. It is congruent with the bank mesh, and has graded resolution such that the Courant number $(\sqrt{ } g H \Delta t / \Delta x)$ is uniform and steep topography and shorelines are resolved. Detided output from this calculation was used to specify wind-band barotropic pressure variations on the bank-scale mesh boundaries.

\section{Distributed Processing}

Limited ship-to-shore bandwidth necessitated a blend of ship- and shore-based computation. The shore station at University of North Carolina (UNC) concentrated on gathering data products from the Internet and processing them for at-sea operations. Included in this task was the computation of the far-field oceanic forecast and the extraction of boundary conditions for the limited-area forecast. The shipboard teams concentrated on gathering and processing in situ data; doing the limited-area forecast; and providing forecast services to shipboard scientists.

\section{Data}

Data products available to us in real-time included the following:

\section{Hydrography}

Hydrographic data were assimilated as initial conditions on the bank mesh. The most recent Bank surveys were objectively analyzed (Hendry and $\mathrm{He}, 2000$ ) to produce a best estimate of bank hydrography prior to the individual cruises (see Figure 4). These were used to initialize our simulations. Periodic supplements of at-sea data were blended with model-generated hydrography to re-initialize the simulations. Satellite-derived sea surface temperature (SST) images were available from the shore-based web server, and used as a qualitative check on this estimation procedure. On-board Conductivity-

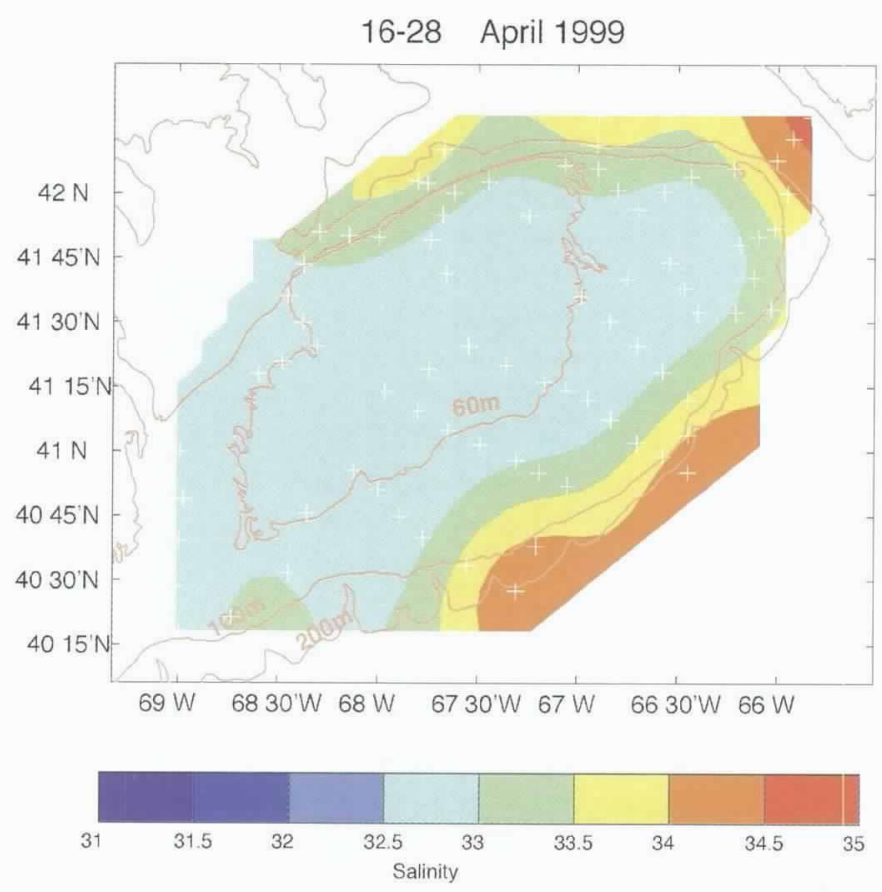

Figure 4. Observed bottom salinity, April 1999. Relative to climatology (Figure 2) perturbations are evident along the North and South flanks. 


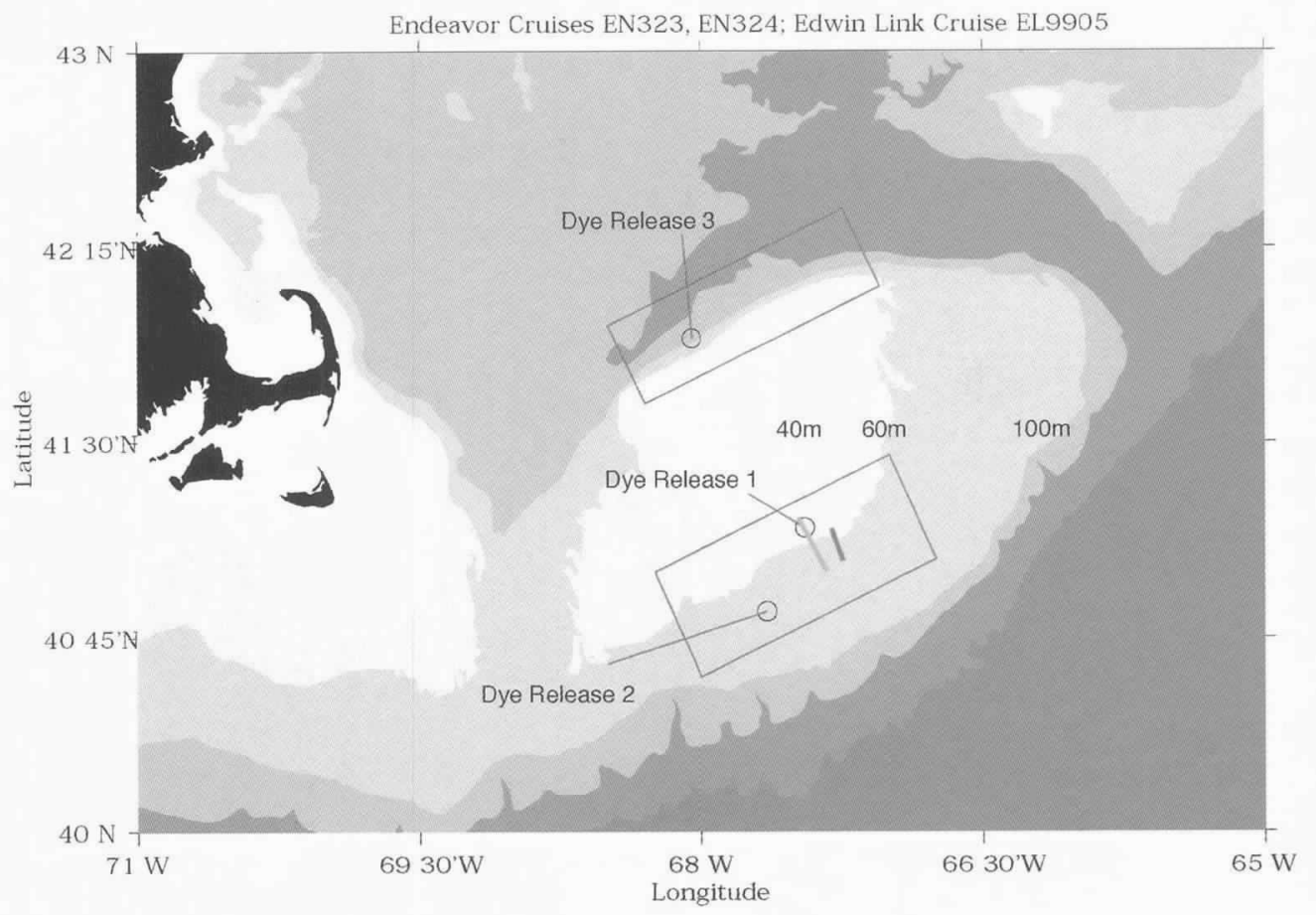

Figure 5. May 1999 operations. $R / V$ Endeavor performed dye release experiments in the boxes shown. $R / V$ Edwin Link surveyed a transect (green line) adjacent to a line of GLOBEC moorings (red line).

Temperature-Depth (CTD) data were available almost instantaneously; data from other ships and all other sources were available subject to network delays. The Endeavor CTD data were collected using the tow-yoed VPR system, providing a vast increase in spatial and temporal resolution over conventional station data.

\section{Meteorology}

Meteorological data available in real-time included direct shipboard observations of wind velocity, temperature, and solar radiation and internet-served time series from the National Data Buoy Center network. (There are 3 stations near Georges Bank which provide wind stress and thermal information.) In addition, we utilized internet-served atmospheric model products from the National Center for Environmental Prediction's (NCEP) Medium Range Forecast Model, sometimes referred to as the Aviation (AVN) model (Kanamitsu, 1989; Betts et al., 1996; AVN, 1999). The AVN output provided 1-day analyzed hindcasts and 3day forecasts for wind and heat flux, updated daily. Resolution of these products was approximately $60 \mathrm{~km}$, so they provided little information about spatial gradients at the bank scale. We forced the bank-scale calculations with shipboard observations, supplemented with the AVN forecast. Preliminary comparisions showed excellent agreement between buoy and shipboard data and reasonable agreement among these observations and hindcast model outputs. We noticed some obvious discrepancies between model wind and shipboard observations which persisted in the AVN analyzed hindcasts. The importance of these will be examined in future sensitivity studies.

\section{Velocity}

Water velocities were estimated using shipboard acoustic Doppler current profilers (ADCPs) and satellite (ARGOS) tracked drifters. The drifters were deployed locally, for specific experimental purposes. 30-minute displacements were converted to velocity observations for assimilation. Additionally, the GLOBEC program supports a baseline drifter program providing routine broader coverage of the Bank. Because these data were sampled too infrequently (6 hours) for existing assimilation schemes, we were unable to utilize them in realtime. Computational experiments with assimilation of Lagrangian displacements will be possible with these data, in hindcast mode.

ADCP data processing took place onboard to provide vertically averaged current velocities for assimilation by the hindcast models. The processing included an automated first level editing to minimize navigation errors and interference with the bottom. During one of the cruises, an initial error in the ADCP heading was identified by the modeling team as a structured, persistent mismatch between reported observations and model results; the heading offset was corrected in realtime in perhaps the first model-assisted real-time ADCP calibration.

Several GLOBEC moorings were in place and operating on the Bank, including a set of bottom-mounted ADCPs and pressure instruments (illustrated in Figure 5). The data from these moorings will be used to evaluate the model forecast runs made at sea as well as subsequent hindcast runs. 
Video Plankton Recorder

A towed Video Plankton Recorder system was deployed from the R/V Endeavor. The VPR was equipped with a CTD, a Chelsea fluorometer, a transmissometer, and two video cameras (high and low magnification) for description of spatially and temporally coincident plankton, dye (Chelsea fluorometer), and

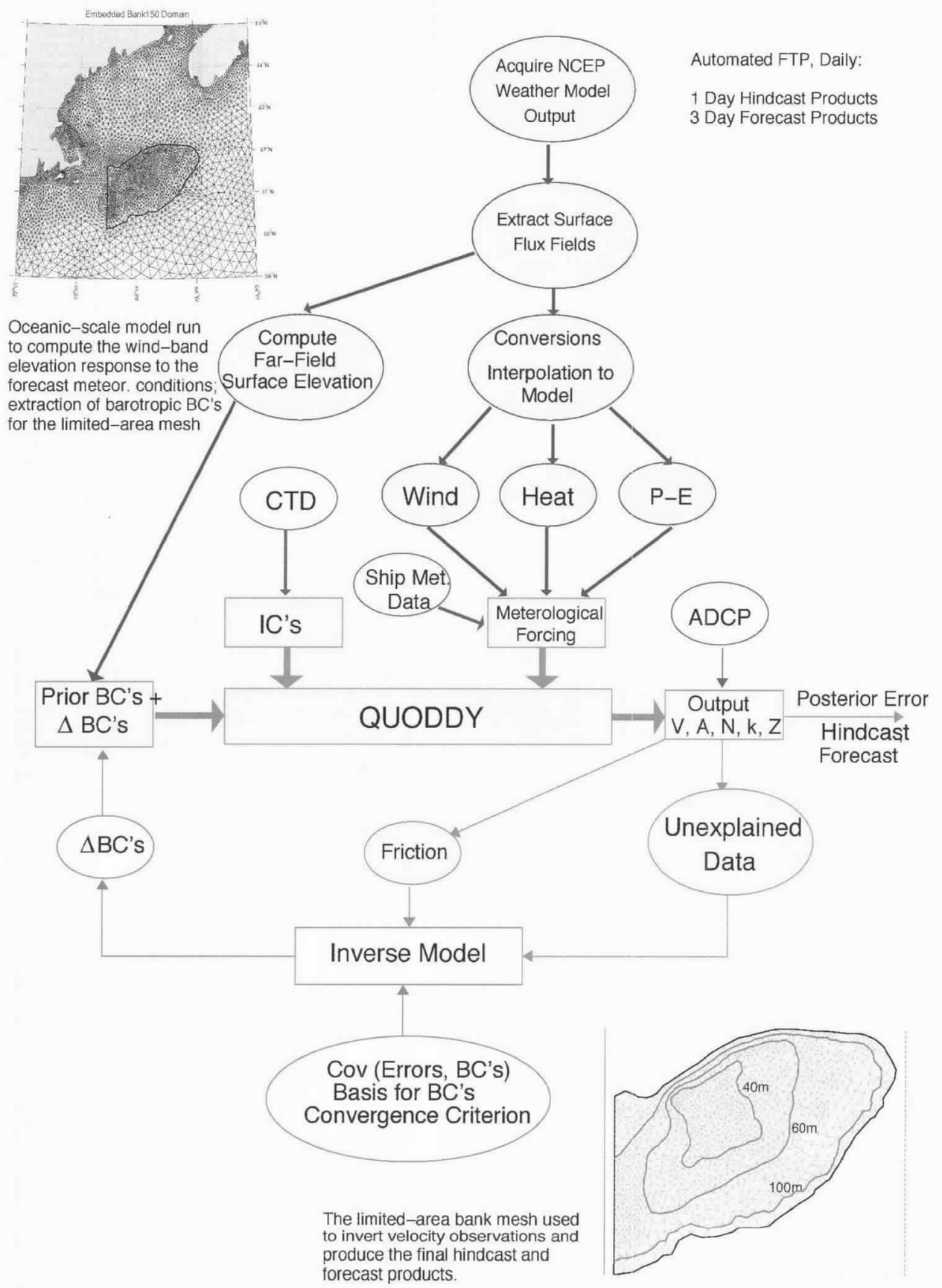

Figure 6. Iterative nonlinear inversion procedure. The oceanic forecast was computed on a wide-area domain (Westerink et al., 1992), forced by weather model forecasts and barotropic tides. Detided barotropic pressure was sampled on the bank-scale mesh boundary (outlined) and used to represent the far-field wind-band response as boundary conditions for the bank-scale calculation. The bank-scale forecast inverted local velocity data to improve boundary conditions. "QUODDY" (Lynch et al., 1996) is the basic simulation engine for the bank-scale. Iteration was used to accommodate its nonlinearities. hydrographic characteristics (e.g. Davis et al., 1992). For plankton identification, individual frames were processed in real-time using a pattern recognition system which identified specific taxa (Davis et al., 1996). The distributions of specific taxa and associated hydrography or dye concentrations then were mapped in realtime (e.g. Gallager et al., 1996; Davis et al., 2000) and passed to the forecast circulation fields to forecast their individual trajectories.

\section{Assimilation Procedure and Real-Time Protocol}

\section{Bank-Scale Forecast}

Our basic simulation engine was QUODDY--a 3-D, nonlinear, prognostic, tideresolving model with advanced turbulence closure (Lynch et al., 1996). This model was operated on the bank-scale mesh and was the heart of the forecast system. There are four aspects to the forecast: the best prior estimate of circulation; the inversion of velocity data to deduce improved boundary conditions; the posterior estimate or hindcast of circulation; and the forecast.

The best prior estimate (BPE) of circulation is a QUODDY simulation, forced as follows. Initial conditions were blended via objective analysis of the latest hydrography, the climatology, and the most recent hindcast. Meteorological forcing was obtained as analyzed/forecast wind and heating fields from the NCEP AVN model. Boundary conditions were the summation of climatological pressure from the Dartmouth archive (tide plus seasonal mean), plus the far-field, wind-band oceanic pressure from our own "oceanic" simulations (described below.)

Discrepancies between the BPE and local velocity data were inverted using the lin- 
earized TRUXTON package (Lynch et al., 1998) to improve the pressure boundary conditions. Iteration was used as in Figure 6 to achieve a nonlinear inversion.

The posterior estimate of the circulation was the final run of this iteration, typically a 5-day hindcast. This run incorporated climatology and the wind-band forcing from the $\mathrm{BPE}$, plus the $\mathrm{ADCP}$-driven $\mathrm{BC}$ supplement from the inversion. The forecast was the extension of this simulation for 3 additional days, using forecast meteorological and oceanic forcing and persistence of the subtidal boundary conditions. Forecasts were updated daily, and published for shipboard use.

\section{Oceanic Forecast}

A separate forecast of oceanic wind-band variability was constructed on the oceanic mesh. The simulator for this forecast was the barotropic model ADCIRC (Luettich et al., 1996). This calculation was driven by a pre-computed, comprehensive tidal baseline, plus the output of the NCEP AVN model for wind stress and barometric pressure. Results were detided and sampled at the boundary of the bank-scale mesh. This provided us with the highest-quality forecast for oceanic pressure available, at the high local resolution demanded by the bank mesh.

\section{Forecast Timing}

The goal of the forecasting system was to issue daily hindcast/forecast products which incorporated the latest possible data. We were able to achieve daily 3-day forecasts and 3- to 5-day hindcasts, with a 3-hour delay for shipboard ADCP data and an additional 9-12 hour

\section{EN323 clim 01}

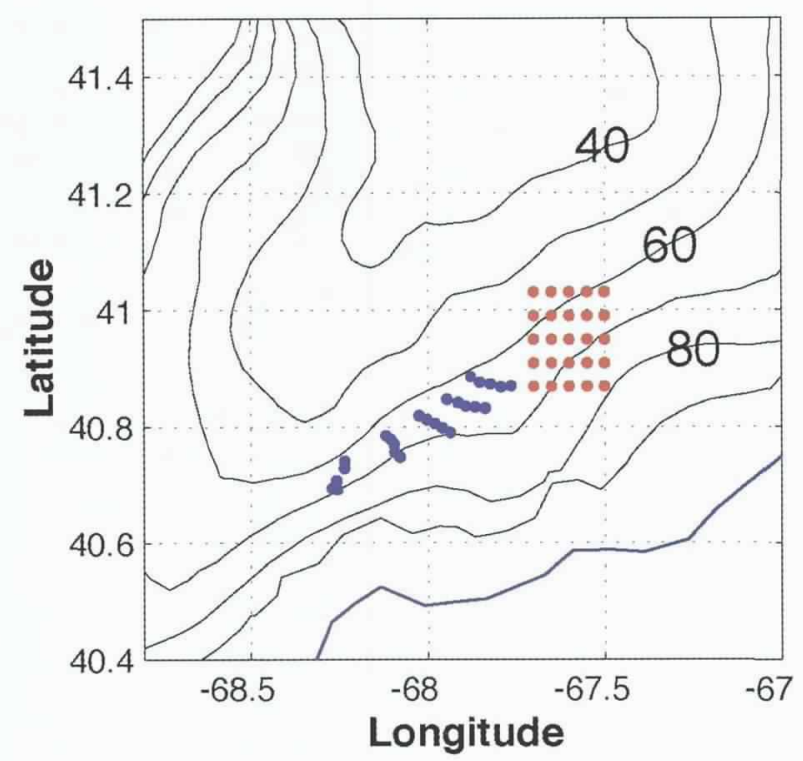

delay for far-field meteorological data. Details are reported below. Shipboard services constituted a standard html display of the forecast plus an interactive capability for its examination and hypothesis testing. (See RT 1999 for an example).

\section{Shakedown Cruise-April 1999}

The first seagoing test occurred aboard R/V EDWIN LINK, 15-25 April 1999. Meteorological conditions on the Bank were quiescent in the period prior to and during most of the cruise. Stratification was typical for this period, resembling climatology.

The first several days were spent establishing basic ship-to-shore communications protocols and the creation of a baseline BPE. A recently-completed hydrographic survey of the Bank in early April (Taylor and Bascunan, 2000) and the various atmospheric products were available for this purpose. Also during this period a baseline forecast display system was automated for shipboard use.

Due to hardware failures within the ADCP deckbox, velocity data for assimilation purposes on this cruise were limited to those deduced from 5 drifter tracks. Assimilation operations began on 20 April and immediately revealed the need to adjust the inversion system to account for the limited velocity data. Additional 3-day forecasts were prepared on 22 and 23 April. On 24 April a major wind event occurred, and operations were terminated.

The best prior estimate of circulation, with no inversion, was remarkably accurate throughout the cruise, until the wind event. This reflects the determinism of

Figure 7. Pre-cruise simulations of proposed Southern Flank dye releases. Launch points (red) and terminal points (blue) of simulated particles are shown under hypothetical conditions. Left: climatological conditions. Right: climatology plus a 25-knot NE wind. 

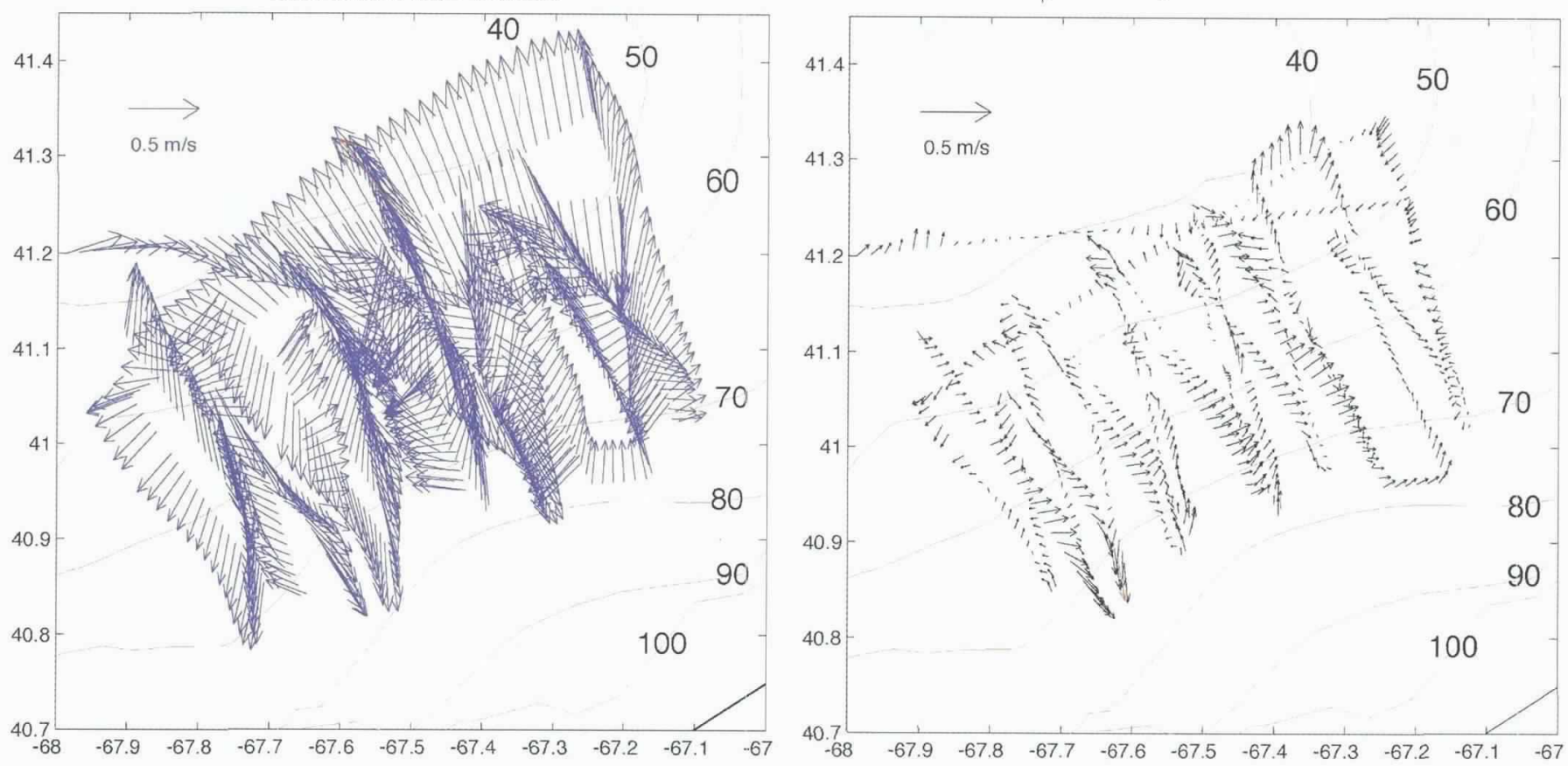

Figure 8. Inversion of ADCP data. The raw, vertically-averaged ADCP data are shown on the left. On the right the post-inversion residual or "unexplained" velocity (data minus model prediction) is shown. The inversion explains $96 \%$ of the ADCP data variance in this case, leaving the residual on the right as "noise." The visible structure in the residual indicates that there is room for improvement in the inversion.

tide, topography, and heating under quiescent conditions in this system.

The wind event was not forecast in the atmospheric products so the oceanic forecast failed to anticipate it. Since the drifters were retrieved during that event for operational/safety reasons, we were unable to study the assimilation skill during this event. Discrepancies among atmospheric products were noted, especially among local shipboard wind and the AVN products. The operational implications of these deserve careful study.

Serious communications limitations were confronted and overcome, but communications are likely to remain a limiting problem in real-time operations. Reproduction of the normal modeling environment was difficult due to bandwidth limitations and publishing delays for various data and computational products. Routine dialog among modelers, who normally communicate via instantaneous email and trade massive data files and images over the Internet, had to be forgone. It is clear that delivery of model-based information to experimental scientists at-sea will require at-sea computation for the time being, deployed in a manner that minimizes the communication bottlenecks. Achieving a high-quality network linking at-sea instruments and scientists with shore-based operations and data services remains a priority.

The timeline achieved in this initial operation was extremely encouraging, with an overall delay of 25 hours for atmospheric observations and 3.5 hours for shipboard measurements. The 25 -hour delay includes a total of 9.5 hours for the 3 separate computational models to run. These calculations are necessarily sequential and their joint run times are assumed to be irreducible in the short term. The balance of this delay (15.5 hours) is due to a) serious network limitations and b) our own learning curve in this first exercise. Shore-to-ship communications and our initial procedure for procuring the NCEP data products imposed important limitations and contributed significantly ${ }^{1}$. Additional delays occurred at sea, between receipt of the oceanic forecast on ship and the final bank-scale calculation. Included were burn-in of the assimilation procedure, tuning of archival strategies, manual examination of incoming data streams, and various scientific investigations. Much of this 15.5 hour delay can be eliminated with further automation of the data feeds and experience. This results in a minimum overall delay of 9.5 hours separating atmospheric data and the publication of a Georges Bank forecast. In the May 1999 cruises we made significant progress toward this minimum.

\section{Final Cruises - May 1999}

The April cruise proved that real-time, at-sea operations were possible. During the May cruises we were able to demonstrate their scientific value.

${ }^{1}$ Communication media were limited to daily email and voice contact via radio. 


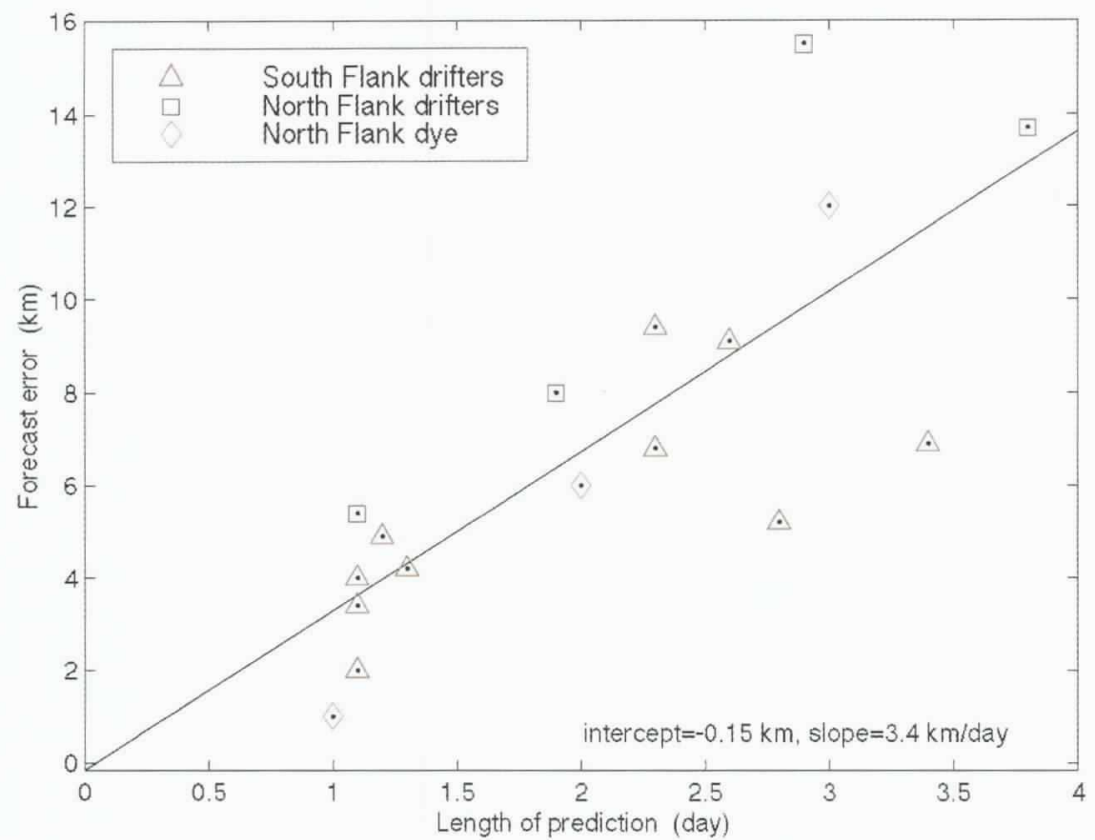

Figure 9. Separation between real and numerically-simulated drifters, versus time. Each datum represents the best of several experimental forecasts. The error growth is 3.4 $\mathrm{km} /$ day, representing a best-case scenario.

\section{Pre-Cruise Simulations}

May operations were focused at the fronts as illustrated in Figure 5. Figures 2 and 3 confirm that these operational targets coincide with the climatological frontal system. Prior to departure, Observational System Simulation Experiments (OSSEs) were undertaken to test the robustness of the observational plan for Endeavor's dye release experiments. Releases were simulated in the climatological frontal system with various credible perturbations. An example appears in Figure 7. These experiments bracketed the likely scenarios and generally confirmed the experimental plan. The relative success during the April cruise lent credibility to these simulations.

\section{Real-time ADCP Inversion}

A typical at-sea inversion of ADCP data is illustrated in Figure 8. The data were obtained as part of a survey of the Southern Flank frontal system in advance of a dye release. We were routinely able to reduce velocity signals of order $50 \mathrm{~cm} / \mathrm{sec}$ to roughly $15 \mathrm{~cm} / \mathrm{sec}$ by subtraction of the BPE, and to below $10 \mathrm{~cm} / \mathrm{sec}$ following inversion. The inversion shown explains $96 \%$ of the raw velocity data variance.

\section{Real-time Drifter Forecast}

Drifters drogued at various depths were routinely deployed to survey the operational $\operatorname{area}^{2}$. The separation distance between real and simulated drifters was used as a measure of forecast skill ${ }^{3}$. Several forecasts were run daily, to evaluate forecast sensitivity to the computational parameters. In Figure 9 we plot the collection of daily best drifter forecasts, versus length of forecast, for the whole cruise. The mean error growth rate between (best) forecast and actual position is $3.4 \mathrm{~km} /$ day. To put this error growth rate in perspective, the tidal displacement is of order $10 \mathrm{~km}$; and the subtidal flow is typically $15-35 \mathrm{~km} /$ day. Since these are the daily best forecasts, as determined in hindsight, this measure needs to be interpreted as an ideal, lower bound on forecast error growth rate. The task remaining for us is to determine the setup of the forecast system so that this 'best' forecast can be selected without the benefit of the verification data. Future improvements in the basic assimilation algorithms may lead to even better performance.

These data correspond to intermediatedepth drifters, drogued near the pycnocline; forecasts of surface drifters were less accurate.

\section{Real-time Dye Forecast}

A variety of different approaches were used to monitor and predict the trajectories of the three dye patches. Each injection was accompanied by the deployment of several drifters within the patch whose movements were tracked using both satellite and radio fixes. In addition, an analog forecast of the dye trajectory was computed via temporal integration of ADCP velocity observations collected during the dye survey operations. Finally, numerical forecasts of the center of mass of the dye patch were computed by releasing clouds of passive particles into forecast flow fields. This model-based procedure is more complex than the analog forecast in that it includes vertical motion and spatial velocity gradients.

In addition to tracking the dye's center of mass, model-generated fields were also used to produce synoptic maps of its horizontal distribution. The need for advective correction to dye observations arises from the fact that it takes a day or more to complete a survey of the patch, during which both tidal and sub-tidal motions cause significant displacements of the water. On this part of the Bank, the M2 tide moves fluid parcels in elliptical motion with a semimajor axis of nearly $10 \mathrm{~km}$; the mean flow is on the order of 10 $\mathrm{cm} / \mathrm{sec}$ toward the southwest. To account for this, fluidfollowing drifters were deployed along the survey track in the model solutions, each tagged with the observed

\footnotetext{
${ }^{2}$ Drogues were designed according to the WOCE standard 40:1 drag ratio. A total of 50 drifter deployments were made in a series of 10 clusters, with $95 \%$ recovery rate.

${ }^{3}$ During May we inverted ADCP data but not drifters; drifter data were reserved for verification of the hindcasts and forecasts.
} 

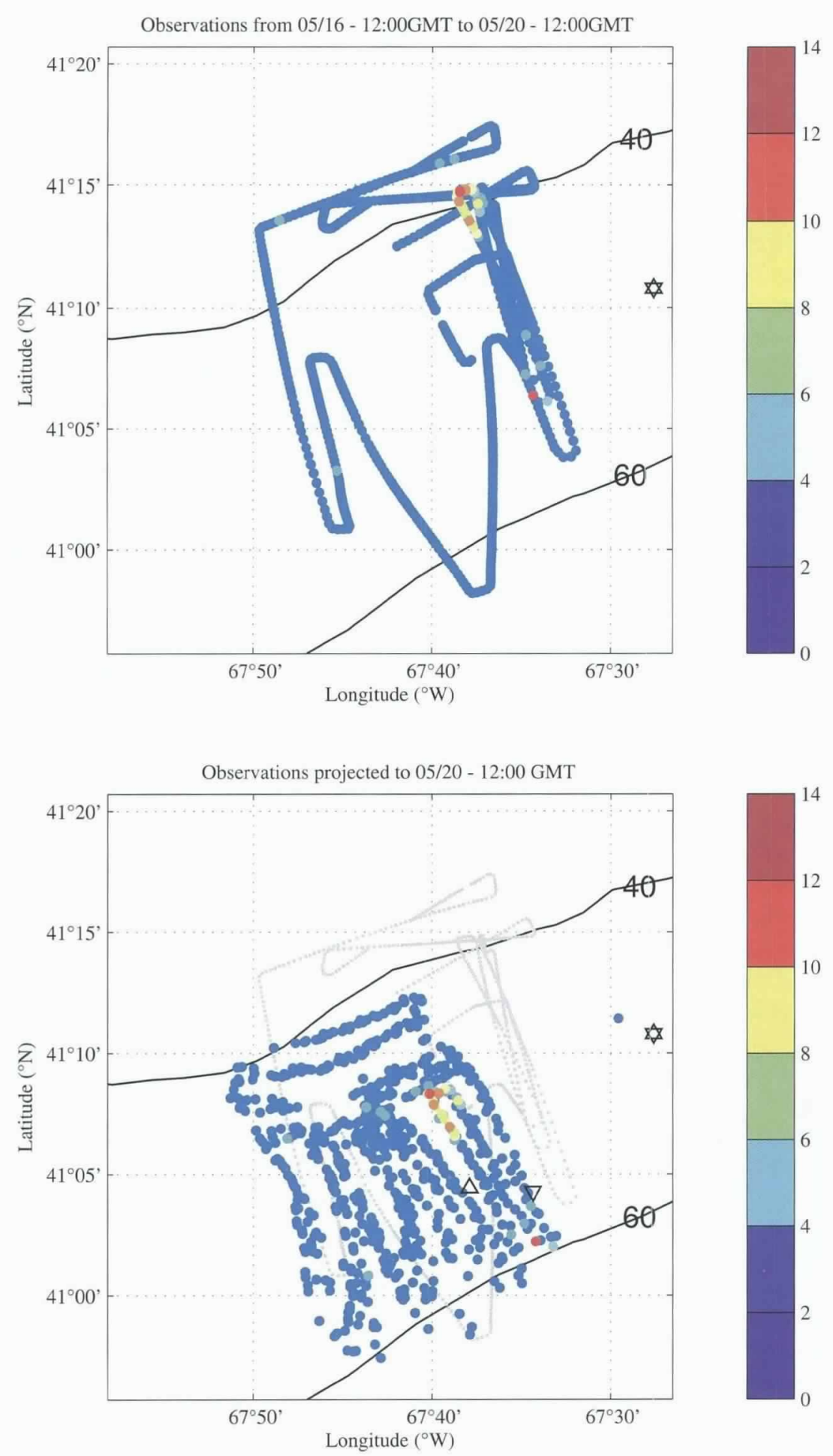

Figure 10. Model-based advective correction of dye observations. Top panel shows the location of the South Flank surface tracer release (star) and the track line of the first dye survey in geographic coordinates. The observed tracer concentration is indicated by dot color. Bottom panel shows the distribution of the same observations advected to the end of the survey (2.8 days after injection) by the modeled velocities. Also shown are the final positions of surface (upwardpointing triangle) and $15 \mathrm{~m}$ (downward-pointing triangle) numerical drifters released in the solution at the site of injection. The grey dots indicate the original geographic locations of the observations. dye concentration. These particles were systematically released at the time of observation and advected forward until the end of the survey. At the final time, the collection of particles represents an estimate of the synoptic distribution of observations based on the modeled velocities, from which the tracer distribution can be mapped. An example of this procedure is shown in Figure 10. The relationship between the geographic positions of the observations and their advected locations at the final time is complex because of the large amplitude, time-dependent flow. Evolution of this relationship is not obvious from static maps at the two endpoints shown in Figure 10; visualization in animated form provides a much more complete presentation of the results (see http://sci ence.whoi.edu/users/mcgillic/globec/ RTDA_paper/dye_mapping.html).

The location of the tracer's center of mass at the final time can be compared with the position of fluid-following particles injected into the forecast solution, providing an estimate of forecast skill. Comparisons based on the North Flank dye release are included in Figure 9.

\section{Real-time VPR Assimilation and Taxon-Specific Forecast}

During the May cruise, populations of copepods (e.g. Calanus finmarchicus) were abundant on the shelf while planktonic hydroids were found on the crest. It has been shown that planktonic hydroids may be significant predators of young stages of C. finmarchicus (e.g. Madin et al., 1996). Both the observed distributions and the real-time modeling simluations demonstrated that little co-occurrence of these two taxa was present. Taxa-specific plankton distributions incorporated into the model demonstrated that different advective regimes in the two major regions of the Bank (crest vs. shelf, separated by the tidal mixing front) affected the potential retention and mixing of organisms and populations. Greater advection of populations to the southwest was observed in the shelf region (copepods) than on the crest (hydroids) (see Figure 11). 


\section{Real-time Forecast Timing}

Figure 12 shows the timeline realized on EN323, 324. In this graphic we represent every piece of scientific information by its location in a 2-D timing space. The vertical axis represents the time of occurrence of an event in nature. The horizontal axis represents the time of availability of information about that event. All observational data necessarily fall below the $45^{\circ}$ line; information above the line is necessarily a forecast. Publication delays separate data from their use in forecasts or hindcasts. Forecast simulations are initiated at the "bell" or closing time; information published after the bell is too late to be assimilated. An assimilation (or computation) delay follows the bell, after which the simulation results are published as a timeseries i.e. a vertical line in the timing space. Each simulation comprises a hindcast period as well as a forecast period.

As can be seen Figure 12, much of the "learning curve" delay from the April cruise was eliminated, and the at-sea computational time was accelerated with a faster workstation. The result is a 16-hour total delay from atmospheric bell to Georges Bank forecast publication. Remaining is a 6-hour publication delay in the atmospheric forecast, which can be reduced as needed. The overall conclusion is that daily 3-day forecasts can be achieved with half-day overall delay.

\section{Conclusions}

Our basic findings are summarized as follows:

- Fast real-time inversions of a state-of-theart 3D shelf model can be made at sea, driven by shipboard ADCP data.

- Real-time data-assimilative forecasts can be made, and forecast products delivered at sea, with assimilative delay of $1 / 2$ day or less for a 3-day forecast.

- Forecast accuracy of $3.4 \mathrm{~km} /$ day appears approachable for drifters and dye patches.

- Real-time assimilation of species-specific plankton locations was achieved.

- Multi-ship operations are possible and were achieved; there are serious networking issues among ships and ship-to-shore.

Relative to the three hypotheses described above, we have ample confirmation of the first hypothesis - fast, high-quality products were delivered to scientists at sea. The inter-
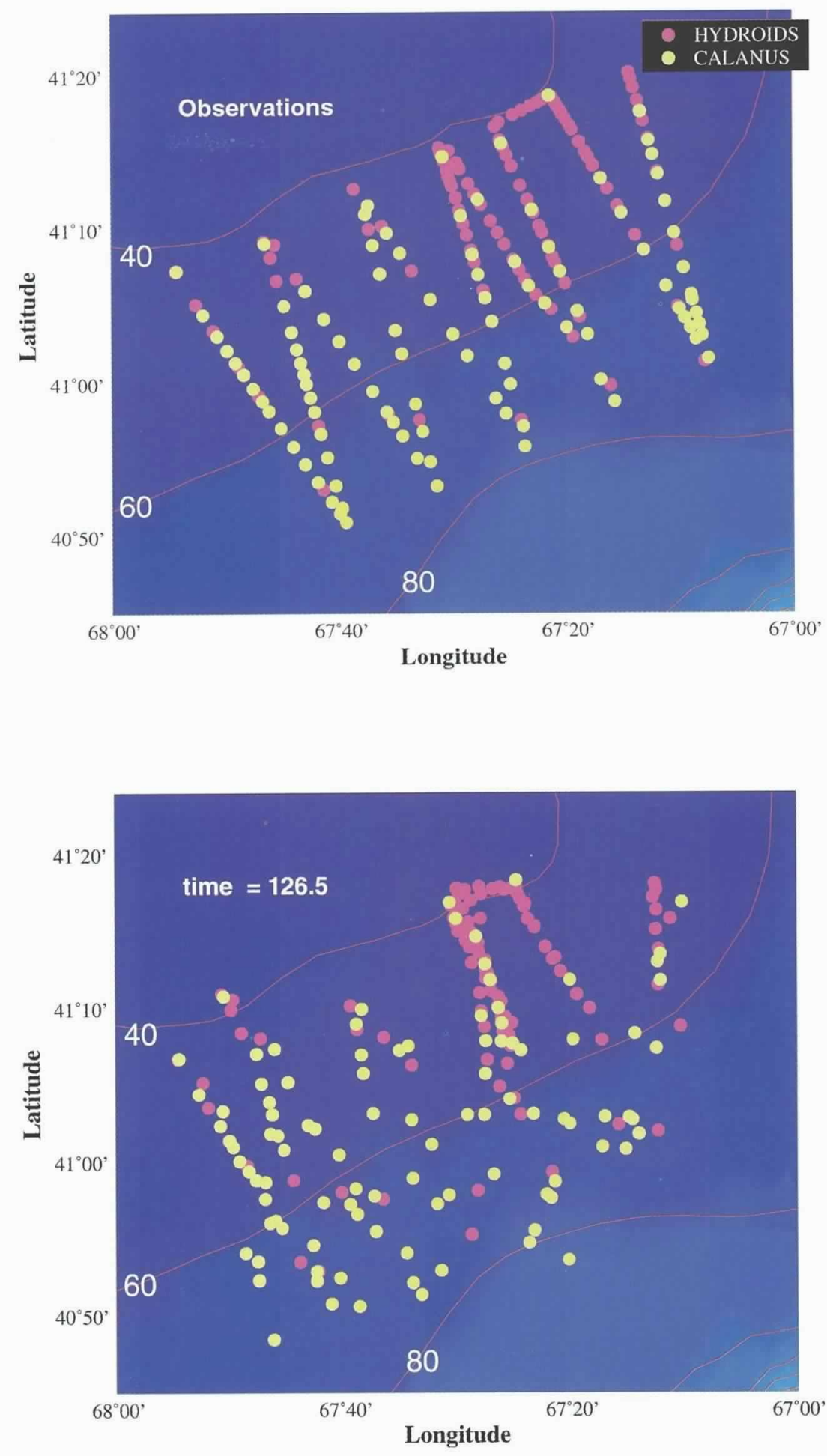

Figure 11. VPR-identified space-time locations for individual Calanus (prey) and hydroids (predator) were advected in the forecast flow field. The top picture shows the non-synoptic observations as taken. The bottom picture shows the same observations, synoptically mapped assuming passive 3-D advection of each individual in the forecast flow field. The Calanus were deeper and further off-bank, and advected to the southwest faster than the hydroids. (Data from Davis et al., 2000.) 


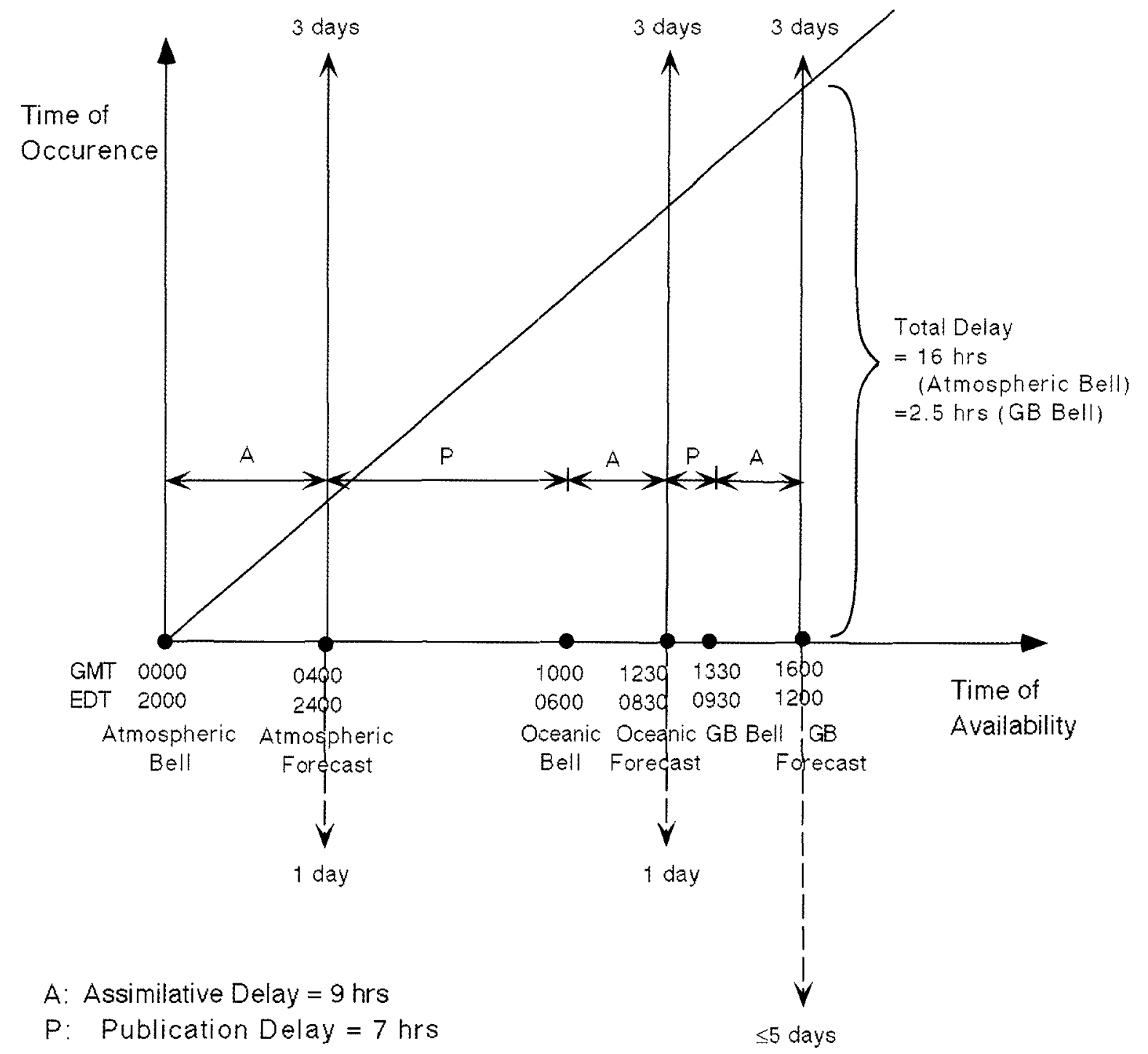

Figure 12. Timeline for cruise EN323, 324. The $y$-axis represents plusical (natural) time; the $x$-axis represents the time of ainilability of information. A hindast/forecast product is initiated at its bell time (closing time for relevent data) and published following an assinilation delay. A single daily cycle of thee sequential forecasts is showen: the public weather model, operated by NCEP; the oceanic model, operated at the UNC shore station; and the Georges Bank model, operated at sea. Each calculation is represented by a vertical line (timeseries) at the point of its availablilty. The dotted line indicates the hindast portion; the solid line, the forccast portion.

est that this information attracted during the cruises suggests confirmation of the second hypothesis - that the products add value to data interpretation at sea. Continued scrutiny of the 1999 outcomes should allow us to be more precise on this point. The last hypothesis, that real-time forecasts can improve sampling, remains formally untested by this experiment. However the system was consulted during operational decision making and we view this as partial confirmation of that hypothesis. Future at-sea trials are justified.

\section{Discussion}

In recent years we have crossed several important scientific thresholds, relative to model sophistication and realism, computational power, and remarkable new instruments including in situ instruments and satellites. Together these are revolutionizing operational oceanography.

Models have the potential to connect general theory to site-specific data and to integrate disparate disciplines. The emergence of "computational science" as a professional field testifies to the value of this function. The real-time deployment of models in the field, while experimental plans can still evolve, provides numerous possibilities. We have demonstrated some of these by assimilating data as diverse as velocity and space-time locations of individual planktonic organisms, and delivering fast, relevant forecasts. We are convinced 
that this type of activity can make a significant difference in our observational programs and in our ability to understand and model the ocean.

There are several needs. Communications bandwidth among ships, shore, moored and drifting instruments, satellites, and autonomous vehicles needs to be a high priority for the research fleet. Related is the need for a generalized data interface. Better models will always be a priority, especially those which couple biological and physical phenomena. And finally, practical data assimilation procedures are needed relative to all data streams. Diligent pursuit of these needs will yield a bright future.

\section{Acknowlegdements}

This work was supported by the USGLOBEC program, a joint undertaking of the National Science Foundation and the National Oceanic and Atmospheric Administration. We thank our numerous colleagues in this program for their encouragement and interest, especially our shipmates aboard EDWIN LINK and ENDEAVOR. This is USGLOBEC Contribution \#170; and Contribution \#10282 of the Woods Hole Oceanographic Institution.

For more information, contact the project web site at http://www-nml.dartmouth.edu/circmods/RTDA. Cruise reports are available from the USGLOBEC Georges Bank Office, http://globec.whoi.edu.

\section{REFERENCES}

AVN, 1999: http://sgi62.wwb.noaa.gov:8080/web2/ web2/tocold1.html

Backus, R.H. and D.W. Bourne, 1987: Georges Bank. MIT Press, Cambridge, 593 pp.

Betts, A., S.-Y. Hong and H.-L. Pan, 1996: Comparison of NCEP-NCAR Reanalysis with 1987 FIFE data. Mon. Wea. Rev., 124, 1480-1498.

Davis, C.S., S.M. Gallager and A.R. Solow, 1992: Microaggregations of oceanic plankton observed by towed video microscopy. Science, 257, 230-232.

Davis, C.S., S.M. Gallager, M. Marra and W.K. Stewart, 1996: Rapid visualization of plankton abundance and taxonomic composition using the Video Plankton Recorder. Deep Sea Res. II, 43, 1947-1970.

Davis, C.S., S.M. Gallager, X. Tang, L. Vincent, C.J. Ashjian and Q. Hu, 2000: Real-time visualization of taxa-specific plankton distributions. (submitted)

Gallager, S.M., C.S. Davis, A.W. Epstein, A. Solow and R.C. Beardsley, 1996: High-resolution observations of plankton spatial distributions correlated with hydrography in the Great South Channel, Georges Bank. Deep Sea Res. II, 43, 1627-1664.

GLOBEC, 1991: GLOBEC Northwest Atlantic Program: GLOBEC Canada/U.S. Meeting on N.W. Atlantic Fisheries and Climate. U.S. Global Ocean Ecosystem Dynamics, Report No. 2.
GLOBEC, 1992: Northwest Atlantic Implementation Plan. U.S. Global Ocean Ecosystem Dynanics, Report No. 6.

Hendry, R. and I. He, 2000: Technical Report on Objective Analysis (OA) Project. In prep, Can. Tech. Rep. Hydrog. Ocean Sci. http://www.mar.dfo-mpo.gc.ca/science/ocean/ coastal_hydrodynamics/oax.html

Kanamitsu, M., 1989: Description of the NMC global data assimilation and forecast system. Weather and Forecasting, 4, 335-342.

Luettich, R.A. Jr., J. Hudgins and C. Goodall, 1996: Initial Results from a Combined Tide and Storm Surge Forecast Model of the U.S. East Coast, Gulf of Mexico and Caribbean Sea. In: 15th Conference on Weather Analysis and Forecasting, American Meteorological Society, Norfolk, 547-550.

Lynch, D.R., J.T.C. Ip, C.E. Naimie and F.E. Werner, 1996: Comprehensive coastal circulation model with application to the Gulf of Maine. Continental Shelf Researcli, 16, 7, 875-906.

Lynch, D.R., C.E. Naimie and C.G. Hannah, 1998: Hindcasting the Georges Bank Circulation, Part I: Detiding. Continental Shelf Research, 18, 607-639.

Madin, L.P., S.M. Bollens, E. Horgan, M. Buler, J. Runge, B.K. Sullivan, G.K. Klein-MacPhee, E. Durbin, A.G. Durbin, D. Van Keuren, S. Plourde, A. Bucklin and M.E. Clarke, 1996: Voracious planktonic hydroids: unexpected predatory impact on a coastal marine ecosystem. Deep-Sea Research II, 43, 1823-1830.

McGillicuddy, D.J. Jr, D.R. Lynch, A.M. Moore, W.C. Gentleman and C.S. Davis, 1998. An Adjoint Data Assimilation Approach to the Estimation of Pseutocalanus spp. Population Dynamics in the Gulf of Maine-Georges Bank Region. Fisheries Oceanography, 7(3/4), 205-218.

Naimie, C.E., 1996: Georges Bank residual circulation during weak and strong stratification periods - Prognostic numerical model results. J. Grophys. Res., 101, 6469-6486.

RT, 1999: http:/ / science.whoi.edu/users/mcgillic/globec/ EN323-4/html/EN323_FC.12/CRUISE_Q4.3/html/ fcast.html.

Taylor, M. and C. Bascunan, 2000: Description of the 1999 Oceanographic Conditions on the Northeast Continental Shelf: Northeast Fisheries Science Center Ref. Doc. 00-01; 121 pp. Available from: National Marine Fisheries Service, 166 Water St., Woods Hole, Ma. 02543-1026.

Westerink, J.J., R.A. Luettich, Jr., A.M. Baptista, N.W. Scheffner and P. Farrar, 1992: Tide and Storm Surge Predictions Using a Finite Element Model, J. Hydraulic Engineering, ASCE 118(10), 1373-1390. DA 